PRICE COVID19 Data Report December 2021

Pakistan Registry of Intensive Care

Ahmed Farooq ${ }^{1}$, Aisha Kulsoom Mufti ${ }^{2}$, Aneela Altaf ${ }^{3}$, Arsalan Rahatullah ${ }^{2}$, Arshad Taqi ${ }^{4}$, Ashok Kumar ${ }^{5}$, Attaur Rehman ${ }^{6}$, Fakhir Raza Haidri ${ }^{7}$, Iqbal Hussain ${ }^{8}$, Irfan Malik ${ }^{9}$, Jodat Saleem $^{9}$, Liaquat Ali $^{10}$, Mobin Chaudhry ${ }^{8}$, Muhammad Sheharyar Ashraf ${ }^{11}$, Mohiuddin Sheikh ${ }^{12}$, Muhammad Ashraf Zia ${ }^{10}$, Muhammad Asim ${ }^{2}$, Muhammad Asim Rana ${ }^{13}$, Muhammad Hayat ${ }^{2}$, Muhammad Nasir Khoso ${ }^{14}$, Naseem Ali Shaikh ${ }^{15}$, Nawal Salahuddin ${ }^{16}$, Qurat-ul-Ain Khan ${ }^{17}$, Rana Imran Sikander ${ }^{18}$, Rashid Nasim Khan ${ }^{19}$, Saadiya Rizvi ${ }^{14}$, Safdar Rehman ${ }^{8}$, Sairah Babar ${ }^{20}$, Syed Muneeb Ali ${ }^{18}$, Abigail Beane ${ }^{21}$, Aasiyah Rashan ${ }^{22}$ Arjen M Dondorp ${ }^{21}$, Chamira Kodippily $^{22}$, Himasha Muvindi ${ }^{22}$, Dilanthi Priyadarshani ${ }^{22}$, Ishara Udayanga ${ }^{22}$, Rashan Haniffa ${ }^{23}$, Sri Darshana ${ }^{22}$, Srinivas Murthy ${ }^{24}$, Thalha Rashan ${ }^{22}$

1 Doctors Hospital, Lahore

2 North West general Hospital, Peshawar

3 Abbasi Shaheed Hospital, Karachi

4 National Hospital \& Research Centre, Lahore

5 Ziauddin Hospital Clifton Campus, Karachi

6 Patel Hospital, Karachi

7 Sindh Institute of Urology \& Transplant (SIUT), Karachi

8 Pakistan Kidney \& Liver Institute, Lahore

9 Lahore General Hospital, Lahore

10 Jinnah Hospital, Lahore

11 Lady Reading Hospital, Peshawar

12 South East Asian Research in Criticalcare Health (SEARCH)

13 Bahria International Hospital, Lahore

14 South City Hospital, Karachi

15 Hameed Latif Hospital, Lahore

16 National Institute of Cardiovascular Diseases, Karachi

17 Ziauddin Hospital North Nazimabad Campus, Karachi

18 Pakistan Institute of Medical Sciences (PIMS), Islamabad

19 Darul Sehat Hospital, Karachi

20 Shaikh Zayed Hospital, Rahim Yar Khan

21 Mahidol Oxford Tropical Medicine Research unit, Bangkok

22 NICS- MORU, Sri Lanka

23 University College London, London

24 The University of British Columbia, Vancouver

\title{
Writing committee:
}

Madiha Hashmi, Thalha Rashan, Aasiyah Rashan, Rashan Haniffa, Abigail Beane

Corresponding author:

Madiha Hashmi; madiha@nicslk.com 


\begin{abstract}
Pakistan Registry of Intensive Care (PRICE) is a platform that has enabled standardized COVID19 clinical data collection based on ISARIC/WHO Clinical Characterization Protocol. The near real-time data platform includes epidemiology, severity of illness, microbiology, treatment and outcomes of patients admitted with suspected or laboratory confirmed COVID19 infection to 67 intensive care and high dependency units across the country. Data has been extracted and analysed at regular intervals to inform stakeholders and improve care practices. This is our 28th report including all patients with suspected or confirmed COVID-19 from 26th March 2020 to 26th December 2021.
\end{abstract}

Key findings from 8624 patients who met eligibility criteria, are as follows:

? Median age of 60 years (IQR 50-70).

? The most common symptoms were shortness of breath $(\mathrm{n}=6428,77.8 \%)$, fever $(\mathrm{n}=$ 6091, 73.8\%), and Cough $(\mathrm{n}=3354,38.9 \%)$

[ The most common comorbidity was hypertension followed by diabetes.

[ During the course of illness 2804 (32.6\%) patients received non-invasive ventilation, whereas 2474 (28.8\%) patients had mechanical ventilation as their highest organ support. In addition, $2246(26.1 \%)$ patients needed haemodynamic support and 1249 (14.7\%) patients required renal replacement therapy as their highest organ support.

? Median APACHE II score was 18

? Overall mortality at ICU discharge was $39.2 \%$

? Increasing age and requirement for invasive mechanical ventilation were independent risk factors for mortality increased the risk of death 


\section{PRICE report on critically ill COVID-19 patients across Pakistan}

\section{Reporting from 26th March 2020 - 26th December 2021}

\section{Background}

Coronavirus disease 2019 (COVID-19), is an ongoing pandemic of viral pneumonia.(1,2) The first case of COVID-19 in Pakistan was confirmed from Karachi on February 26, 2020, and similar to other countries, Pakistan experienced an upsurge in COVID-19 infections.1287393 confirmed cases and 28784 deaths have been reported since the beginning of pandemic (3). There is paucity of clinical characterization data from low- and middle-income countries such as Pakistan for critically ill COVID-19 patients. (4-7). The Pakistan Registry of Intensive Care (PRICE), established in 2018, and part of the Wellcome funded "CRIT Care Asia" recruits more than 2000 monthly critical care admissions across a national network in Pakistan (8).

Aim of this report is to provide clinicians and stakeholders in critical care services in Pakistan with real-time information regarding the incidence, clinical character and service utilisation throughout the COVID-19 pandemic.

\section{Methods}

The same PRICE platform was adapted to incorporate ISARIC/WHO Clinical Characterization Protocol (CCP) tiers 0-3 capturing clinical and epidemiological data of patients admitted to the collaborating high dependency (HDU) and intensive care units (ICU) with clinically suspected or 
laboratory confirmed COVID19 infection (9). A detailed description of data platform adaptation, data collection method and data management was published previously (9). Variables were added using a standardized nomenclature, Systematized Nomenclature of Medicine Clinical Terms (SNOMED CT), that was already operationalized in the platform, enhancing interoperability at the organizational level and facilitating sharing with ISARIC (10). Data is captured contemporaneously to clinical care via the digital platform, with $24 \mathrm{hr}$ cadence. Inbuilt field validation and range checks promote data quality. Data completeness for ISARIC tiers 0 and 1 was above $97 \%$ during a recent external performance review (11).

\section{Data source}

Information is entered in real-time from 67 participating units from 31 hospitals across the country and provides:

[. A notification when a suspected case of COVID-19 is admitted

[. Admission data for suspected COVID-19 cases, including demographics, characteristics, symptoms at presentation, comorbidities and travel history within 14 days

? Severity of illness,_severity of illness assessed by Acute Physiology And Chronic Health Evaluation II (APACHE II) score

? Daily assessment of organ support and clinical treatments

? Discharge information, including status and outcome of any investigations to confirm COVID-19 diagnosis.

? All the enrolled patients in the registry were followed up to discharge and/or death.

? Statistical analysis was performed using $\mathrm{R}$ software ( $\mathrm{R}$ core team 2021).

The PRICE team are committed to ensuring the registry provides high quality information, whilst recognising the need for timely accessible information during these events. As such this information is collated and reported 'as captured'. This information may undergo revision as analysis evolves and is disseminated for the purpose of primary stakeholders to support clinical care and resource allocation.

\section{Results}


medRxiv preprint doi: https://doi.org/10.1101/2022.01.20.22269202; this version posted January 23, 2022. The copyright holder for this preprint (which was not certified by peer review) is the author/funder, who has granted medRxiv a license to display the preprint in perpetuity.

It is made available under a CC-BY-NC-ND 4.0 International license .

This is the twenty-eighth report summarising the data on all suspected or confirmed COVID-19 cases from the 26th March 2020 to 26th December 2021 admitted to critical care units within the PRICE network that agreed to report data on severe acute respiratory infection (SARI).

\section{Number of Admissions}

A total of 8624 critical care admissions with suspected or confirmed SARI were reported (Figure 1).

Figure 1: Number of ICU admissions with suspected or confirmed SARI by units.

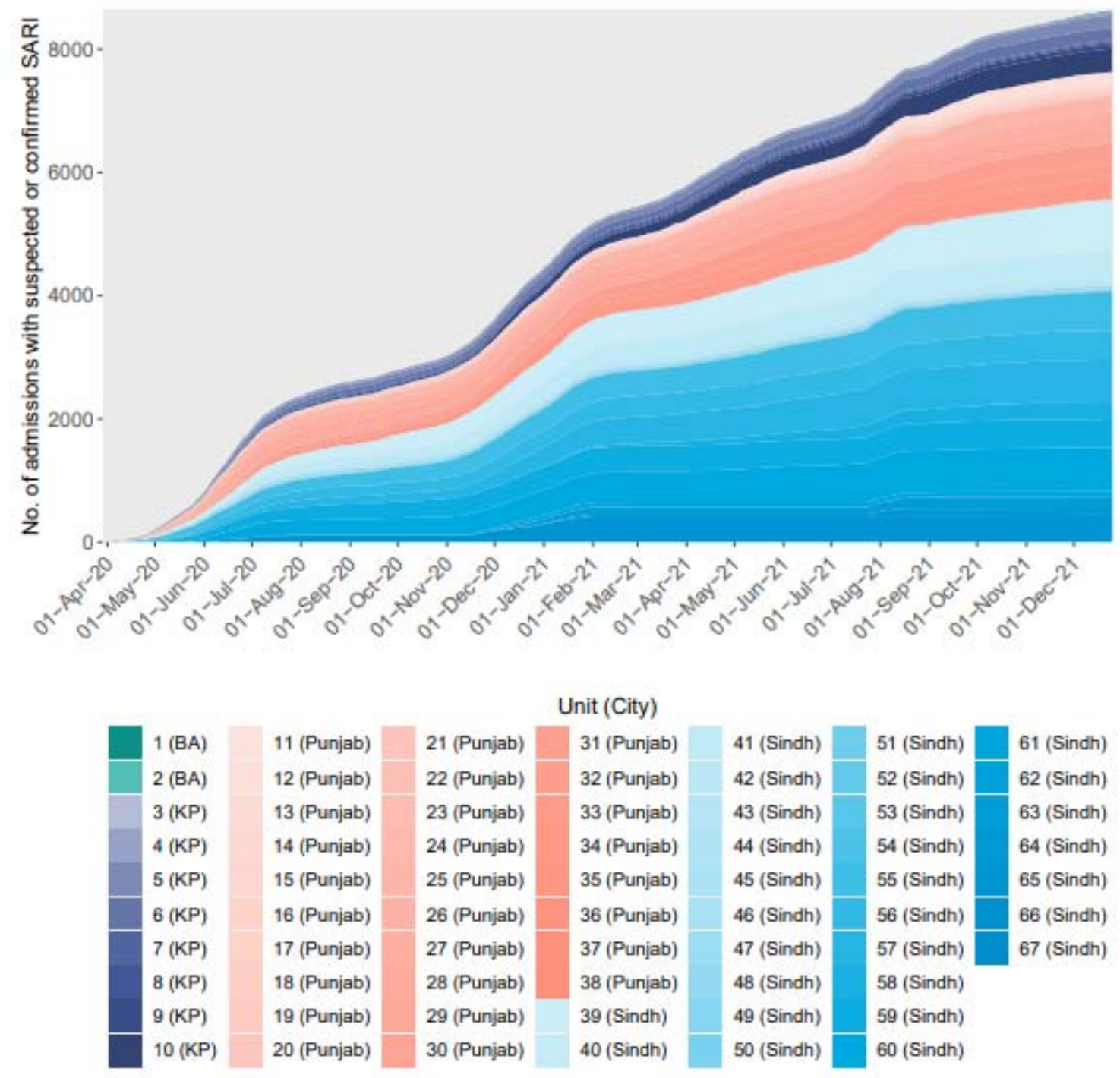


medRxiv preprint doi: https://doi.org/10.1101/2022.01.20.22269202; this version posted January 23, 2022. The copyright holder for this preprint (which was not certified by peer review) is the author/funder, who has granted medRxiv a license to display the preprint in perpetuity. It is made available under a CC-BY-NC-ND 4.0 International license.

\section{Characteristics of admitted patients}


Characteristics of patients with suspected SARI admitted to participating critical care units are summarised in Table 1 and 2, and these are compared with the characteristics of critically ill patients with non-SARI viral pneumonia during 2018-2021 from the same registry. The most common presenting symptoms were shortness of breath, fever and cough with no sputum.

Table 1: Demographics and medical history of admitted patients.

\begin{tabular}{|c|c|c|}
\hline Demographics & $\begin{array}{l}\text { Patients with suspected or } \\
\text { confirmed SARI and } \\
\text { admission data }(\mathrm{N}=8624)\end{array}$ & $\begin{array}{l}\text { Patients with viral pneumonia } \\
\text { (non-SARI), 2018-2021 } \\
(\mathrm{N}=153)\end{array}$ \\
\hline \multicolumn{3}{|l|}{ Age at admission (years) } \\
\hline Mean (SD) & $58.6(15.7)$ & $53.6(19.6)$ \\
\hline Median (IQR) & $60.0(50.0,70.0)$ & $56(38.0,68.0)$ \\
\hline \multicolumn{3}{|l|}{ Sex, n $(\%)$} \\
\hline Male & $5,384(62.4)$ & $86(56.2)$ \\
\hline Female & $3,237(37.5)$ & $67(43.8)$ \\
\hline Currently pregnant, $\mathrm{n}$ (females) $[\mathrm{N}=1560]$ & $87(5.6)$ & $*$ \\
\hline \multicolumn{3}{|l|}{ Ethnicity, n (\%) [N=8200] } \\
\hline Black & $3(0.0)$ & $*$ \\
\hline East Asian & $10(0.1)$ & $*$ \\
\hline Other & $2(0.0)$ & * \\
\hline South Asian & $8,178(99.7)$ & $*$ \\
\hline West Asian & $6(0.1)$ & $*$ \\
\hline White & $1(0.0)$ & $*$ \\
\hline \multicolumn{3}{|l|}{ Medical history } \\
\hline \multicolumn{3}{|l|}{ Comorbidities, n (\%) [N=8624] } \\
\hline At least one comorbidity present & $5,502(63.8)$ & $66(43.1)$ \\
\hline Hypertension & $4,005(46.4)$ & $52(34.0)$ \\
\hline Diabetes & $1,686(19.6)$ & $42(27.5)$ \\
\hline Type 2 Diabetes & $1,033(12.0)$ & $0(0.0)$ \\
\hline Cardiovascular diseases & $736(8.5)$ & $3(2.0)$ \\
\hline
\end{tabular}


Type 1 Diabetes

Other comorbidity

Asthma

Depression

Cerebrovascular disease

Hypothyroidism

Renal failure, Moderate to severe

Dementia

Respiratory disease, Severe moderate

Renal failure, Mild

Chronic pulmonary disease

Respiratory disease, Mild

CKD requiring dialysis

Angina

Tuberculosis

Valve disease

Obesity

Congestive heart failure

Other neurological condition

Hepatic disease, Moderate to severe

Hepatic disease, Mild

Type 1 diabetes with complications

Myocardial infarction

Hyperthyroidism

Epilepsy

Diabetes with complications
$493(5.7)$

$0(0.0)$

$260(3.0)$

$0(0.0)$

$259(3.0)$

$1(0.7)$

105 (1.2)

$0(0.0)$

$96(1.1)$

$2(1.3)$

$82(1.0)$

$0(0.0)$

$59(0.7)$

$1(0.7)$

$54(0.6)$

$0(0.0)$

$53(0.6)$

$1(0.7)$

$51(0.6)$

$2(1.3)$

$48(0.6)$

$0(0.0)$

$48(0.6)$

$0(0.0)$

$47(0.5)$

$0(0.0)$

$37(0.4)$

$1(0.7)$

$29(0.3)$

$1(0.7)$

$23(0.3)$

$1(0.7)$

$23(0.3)$

$0(0.0)$

$22(0.3)$

$0(0.0)$

$18(0.2)$

$0(0.0)$

$18(0.2)$

$0(0.0)$

$16(0.2)$

$0(0.0)$

$16(0.2)$

$0(0.0)$

$15(0.2)$

$0(0.0)$

$15(0.2)$

$0(0.0)$

$15(0.2)$

$0(0.0)$

$15(0.2)$

$0(0.0)$ 
Rheumatological condition

Type 2 diabetes with complications

Tumor

Peripheral vascular disease

Hyperlipidemia

Inflammatory bowel

HIV

Interstitial lung disease

Peptic ulcer

Malignant neoplasm

Arrhythmia

Metastatic cancer

AIDS

Leukemia

Chronic hematologic disease

GI bleeding

Lymphoma

Primary lung cancer

Non diabetic endocrine

Malnutrition
$14(0.2)$

$10(0.1)$

$7(0.1)$

$7(0.1)$

$0(0.0)$

$7(0.1)$

$0(0.0)$

$6(0.1)$

$0(0.0)$

$5(0.1)$

$0(0.0)$

$4(0.0)$

$0(0.0)$

$4(0.0)$

$0(0.0)$

$4(0.0)$

$0(0.0)$

$3(0.0)$

$0(0.0)$

$2(0.0)$

$0(0.0)$

$2(0.0)$

$0(0.0)$

$2(0.0)$

$0(0.0)$

$2(0.0)$

$0(0.0)$

$1(0.0)$

$0(0.0)$

$1(0.0)$

$0(0.0)$

$1(0.0)$

$0(0.0)$

$1(0.0)$

$0(0.0)$

$1(0.0)$

$0(0.0)$

1 *Data not available prior to SARI data collection.

2 Includes patients with confirmed viral pneumonia $(\mathrm{n}=274)$ and those with pneumonia (other, but not bacterial or fungal)) $(\mathrm{n}=99)$ 
Table 2: Clinical characteristics on admission

\section{Presenting characteristics}

Patients with suspected or confirmed SARI and admission data $(\mathrm{N}=8624)$
Patients with viral pneumonia (non-SARI), 2018-2021 $(\mathrm{N}=153)$

\begin{tabular}{|c|c|c|}
\hline $\begin{array}{l}\text { History of travel in the last } 14 \text { days, } n(\%) \\
{[\mathrm{N}=8149]}\end{array}$ & $51(0.6)$ & * \\
\hline \multicolumn{3}{|l|}{ Symptoms, n (\%) [N=8258] } \\
\hline Shortness of breath & $6,428(77.8)$ & * \\
\hline History of fever & $6,091(73.8)$ & $*$ \\
\hline Cough with no sputum & $2,229(27.0)$ & $*$ \\
\hline Cough with sputum & $1,125(13.6)$ & * \\
\hline Sore throat & $1,025(12.4)$ & $*$ \\
\hline Muscle aches & $467(5.7)$ & $*$ \\
\hline Chest pains & $444(5.4)$ & * \\
\hline Altered consciousness/ Confusion & $311(3.8)$ & $*$ \\
\hline Fatigue/Malaise & $301(3.6)$ & * \\
\hline Vomiting/nausea & $286(3.5)$ & $*$ \\
\hline Diarrhoea & $217(2.6)$ & $*$ \\
\hline Abdominal Pain & $179(2.2)$ & $*$ \\
\hline Wheezing & $168(2.0)$ & $*$ \\
\hline Headache & $154(1.9)$ & $*$ \\
\hline Joint pain & $87(1.1)$ & $*$ \\
\hline Runny nose & $80(1.0)$ & $*$ \\
\hline Inability to walk & $56(0.7)$ & $*$ \\
\hline Cough with bloody sputum/haemoptysis & $47(0.6)$ & $*$ \\
\hline Loss of taste & $42(0.5)$ & $*$ \\
\hline Seizures & $32(0.4)$ & $*$ \\
\hline Bleeding & $30(0.4)$ & $*$ \\
\hline Loss of smell & $23(0.3)$ & $*$ \\
\hline Asymptomatic & $21(0.3)$ & * \\
\hline
\end{tabular}


Lower chest wall indrawing

Anorexia

Conjunctivitis

Skin rash

Ear pain

Skin ulcers
$11(0.1)$

$7(0.1)$

$3(0.0)$

$3(0.0)$

$1(0.0)$

$1(0.0)$
$*$

$*$

$*$

$*$

$*$

$*$

\section{Severity of illness at anytime during ICU} stay

\section{Highest Organ support received at anytime during ICU stay, n (\%)}

Invasive ventilation [ $\mathrm{N}=8597]$

Non-invasive ventilation [ $\mathrm{N}=8597]$

Cardiovascular support [ $\mathrm{N}=8603]$

Renal replacement therapy [ $\mathrm{N}=8495]$

ECMO [N=6266]

Prone ventilation $[\mathrm{N}=8258]$
$2,474(28.8)$

$54(35.3)$

$2,804(32.6)$

$2,246(26.1)$

$1,249(14.7)$

$00(00)$

$3,111(37.7)$
$22(14.4)$

$40(26.1)$

$10(6.5)$

*

$4(2.6)$

\section{Antimicrobial use at admission}

Prescribed at admission, $\mathrm{n}(\%)$

Antimicrobial type, n (\%)

Piperacillin + Tazobactam

Meropenem

Azithromycin

Remdesivir

Ceftriaxone

Vancomycin

Levofloxacin

Moxifloxacin
3,061 (35.5)

2,243 (26.0)

$1,755(20.4)$

$1,210(14.0)$

$920(10.7)$

539 (6.2)

$363(4.2)$

$322(3.7)$
$36(23.5)$

$44(28.8)$

$26(17.0)$

$0(0.0)$

$28(18.3)$

15 (9.8)

$3(2.0)$

$4(2.6)$ 
Colistin(polymixin E)

Other antibiotic

Metronidazole(Flagyl)

Linezolid

Trimethoprim/Sulfamethoxazole

Ivermectin

Imipenem + Cilastatin

Trazabactum

Voriconazole

Teicoplanin

Cefoperazone + Sulbactum

Invermectin

Tigecycline

Acyclovir

Doxycycline

Amikacin

Augmentin

Cefixime

Erythromicine

Dexamethasone

Ciprofloxacin

Ceftazidime

Fluconazole
$170(2.0)$

$9(5.9)$

138 (1.6)

2 (1.3)

$116(1.3)$

$8(5.2)$

$74(0.9)$

$3(2.0)$

$69(0.8)$

$0(0.0)$

$69(0.8)$

$0(0.0)$

$60(0.7)$

$1(0.7)$

55 (0.6)

4 (2.6)

48 (0.6)

$0(0.0)$

$46(0.5)$

$0(0.0)$

$43(0.5)$

$3(2.0)$

$29(0.3)$

$0(0.0)$

$29(0.3)$

2 (1.3)

$29(0.3)$

$1(0.7)$

$26(0.3)$

$0(0.0)$

$24(0.3)$

2 (1.3)

$21(0.2)$

$1(0.7)$

$21(0.2)$

$0(0.0)$

$18(0.2)$

$0(0.0)$

$17(0.2)$

$0(0.0)$

$17(0.2)$

$0(0.0)$

$12(0.1)$

$0(0.0)$

$11(0.1)$

$0(0.0)$ 
Cefotaxime

Clarithromycin

Clindamycin

Cefoperazone

Cefepime

Amphotericin-B

Cefuroxime

Baricitanib

Amoxicillin

Cefazolin

Favipiravir

Tobramycin

HCQ+ Oseltamavir

Oseltamavir

Co-amoxiclav

Penicillin

Antifungal

Ertapenem

Rifampicin

Timentin

Polymyxin

Actemira

Att
$10(0.1)$

$10(0.1)$

$10(0.1)$

$9(0.1)$

$8(0.1)$

$5(0.1)$

$5(0.1)$

$0(0.0)$

$4(0.0)$

$0(0.0)$

$4(0.0)$

$0(0.0)$

$3(0.0)$

$0(0.0)$

$3(0.0)$

$0(0.0)$

$3(0.0)$

$0(0.0)$

$2(0.0)$

$0(0.0)$

$2(0.0)$

$0(0.0)$

$2(0.0)$

$0(0.0)$

$2(0.0)$

$0(0.0)$

$2(0.0)$

$0(0.0)$

$2(0.0)$

$0(0.0)$

$2(0.0)$

$0(0.0)$

$2(0.0)$

$0(0.0)$

$2(0.0)$

$0(0.0)$

$1(0.0)$

$0(0.0)$

$1(0.0)$

$0(0.0)$ 


\begin{tabular}{|c|c|c|}
\hline Dexamethasone & $1(0.0)$ & $0(0.0)$ \\
\hline Vibramycin/ Tocilizumab & $1(0.0)$ & $0(0.0)$ \\
\hline Actemra & $1(0.0)$ & $0(0.0)$ \\
\hline Arbidol & $1(0.0)$ & $0(0.0)$ \\
\hline Tocilizumab & $1(0.0)$ & $0(0.0)$ \\
\hline Salbutanol & $1(0.0)$ & $0(0.0)$ \\
\hline Azitma 500mg & $1(0.0)$ & $0(0.0)$ \\
\hline Velosef & $1(0.0)$ & $0(0.0)$ \\
\hline Dexamthasone & $1(0.0)$ & $0(0.0)$ \\
\hline Vibramycine & $1(0.0)$ & $0(0.0)$ \\
\hline Vinzet & $1(0.0)$ & $0(0.0)$ \\
\hline Tienum,Actemra & $1(0.0)$ & $0(0.0)$ \\
\hline Cotrimoxazole & $1(0.0)$ & $0(0.0)$ \\
\hline Aztreonam & $1(0.0)$ & $0(0.0)$ \\
\hline Ampicillin / Sulbactam & $1(0.0)$ & $0(0.0)$ \\
\hline Isoniazid & $1(0.0)$ & $1(0.7)$ \\
\hline Ampicillin & $1(0.0)$ & $0(0.0)$ \\
\hline Caspofungin & $1(0.0)$ & $0(0.0)$ \\
\hline Doxophylline & $1(0.0)$ & $0(0.0)$ \\
\hline
\end{tabular}

\section{APACHE II Score}

Mean (SD)

Median(IQR)
$19.3(7.4)$

$22.2(8.2)$

$18(14.0,23.0)$
$21(16.0,28.0)$ 
medRxiv preprint doi: https://doi.org/10.1101/2022.01.20.22269202; this version posted January 23, 2022. The copyright holder for this preprint (which was not certified by peer review) is the author/funder, who has granted medRxiv a license to display the preprint in perpetuity.

It is made available under a CC-BY-NC-ND 4.0 International license .

1 Data not available prior to SARI data collection.

2 Includes patients with confirmed viral pneumonia $(\mathrm{n}=81)$ and those with pneumonia (other, but not bacterial or fungal)) $(\mathrm{n}=58)$

\section{Care provided in critical care and discharge status}

Discharge data was available for 8521 patients. There were 5183 patients discharged alive from critical care (Figure 2). Table 3 outlines the length of stay and outcome for critical care admissions, and compares it with non-SARI viral pneumonia patients during 20182021.

Figure 2: Patient outcomes at ICU discharge

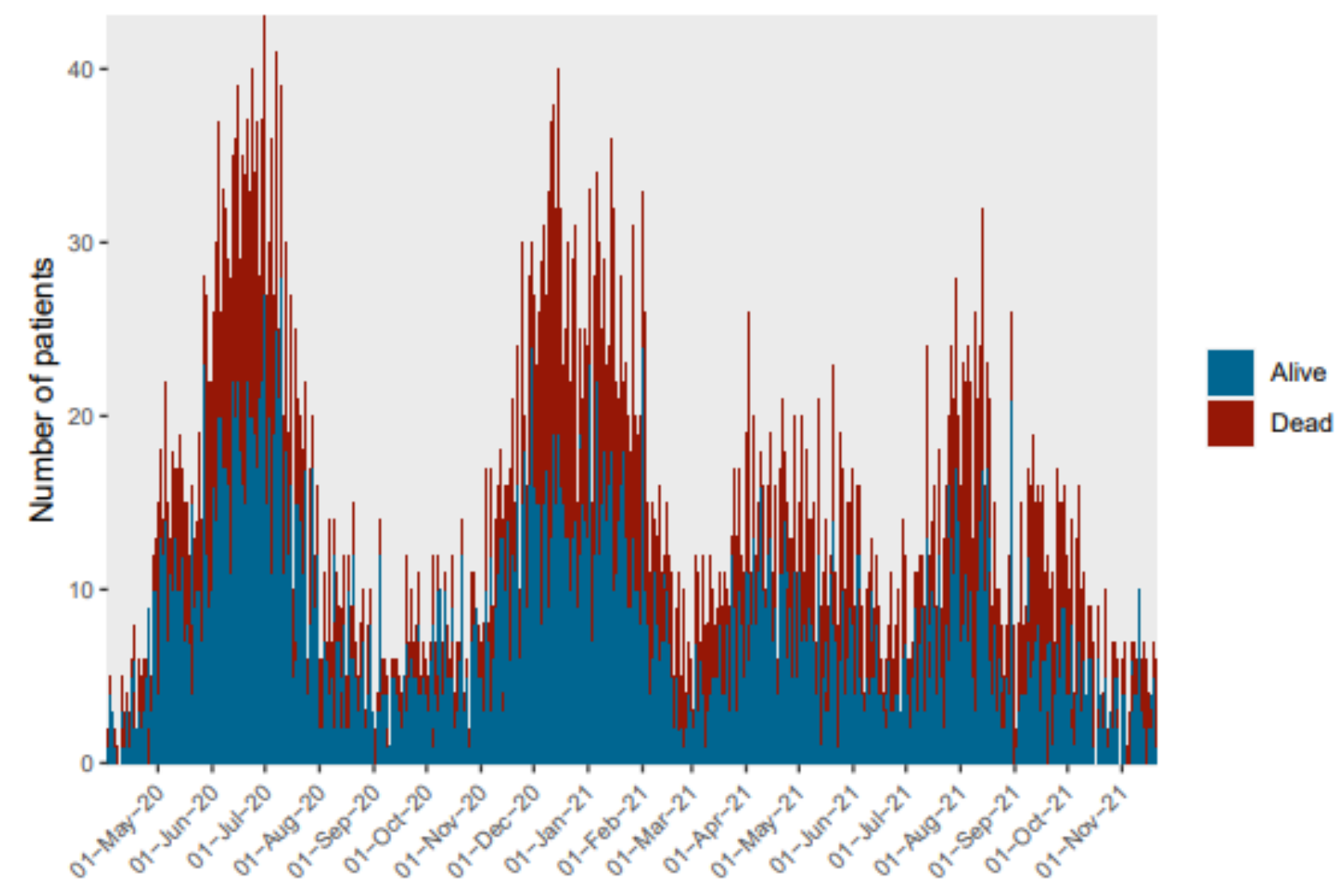

COVID-19 vaccine information

(Capturing COVID-19 vaccine information in the registry was enabled from 9th July 2021) 
One thousand six hundred seventy-five critical care admissions of suspected or confirmed SARI have been notified from 9th July 2021 to 26th December 2021. Of them, COVID-19 vaccine information has been received for $841(50.2 \%)$ patients. There, $321(38.2 \%)$ patients were vaccinated while $520(61.8 \%)$ patients have not got any COVID-19 vaccine.

Table 5: COVID-19 vaccine information of the patients admitted to critical care with suspected or confirmed SARI

\begin{tabular}{|lc|}
\hline Vaccine status & Count $[\mathrm{N}=841]$ \\
\hline Vaccinated, $\mathbf{n}(\%)$ & $321(38.2)$ \\
First dose received & $321(100.0)$ \\
Second dose received & $151(47.0)$ \\
Booster dose received & $8(2.5)$ \\
Non vaccinated, $\mathbf{n}(\boldsymbol{\%})$ & $520(61.8)$ \\
\hline
\end{tabular}

Of 321 vaccinated patients, all have received their first dose, while $151(47 \%)$ have received their second dose. 8 patients $(2.5 \%)$ have received their booster dose.

Table 3: Outcome and length of stay for patients admitted to critical care with suspected or confirmed SARI

Critical care unit outcome
Patients with suspected or confirmed SARI and discharge data $(\mathrm{N}=8521)$
Patients with viral pneumonia (non-SARI), 2018-2021 (N=153)

COVID-19 confirmed at discharge, $\mathrm{n}(\%)$

$6234(82.3)$

$*$

[N=7579]

Outcome at ICU discharge, $n(\%)[\mathrm{N}=8521]$

Alive

107 (69.9)

Deceased

3,338 (39.2)

$46(30.1)$

Outcome for patients invasively ventilated at admission, $n(\%)[\mathrm{N}=1560]$

Alive

$421(27.0)$

23 (47.9)

Deceased

$1,139(73.0)$

$25(52.1)$

Outcome for patient non-invasively ventilated at admission, $n(\%)[\mathrm{N}=1742]$

Alive 
Deceased

Outcome for vaccinated patients (at least one dose received), $n(\%)[\mathrm{N}=298] * *$

Alive

Deceased

Outcome for non-vaccinated

patients, $n(\%)[\mathrm{N}=479]$

Alive

Deceased

Length of stay in critical care (days), median (IQR)

Alive

Deceased
843 (48.4)

198 (66.4)

$100(33.6)$

$300(62.6)$

179 (37.4)

$3.4(1.7,6.1)$

$4.0(1.6,8.0)$
$4.0(1.9,6.8)$

$4(40.0)$

$*$

$*$

$2.5(0.8,5.9)$

\footnotetext{
*Data not available prior to SARI data collection.

$2 * *$ Vaccine information was enabled in the registry from 9th July 2021.

3 Includes patients with confirmed viral pneumonia ( $\mathrm{n}=81)$ and those with pneumonia (other, but not bacterial or fungal)) ( $\mathrm{n}=58$ )
}

Acknowledgement: The authors would like to acknowledge all the collaborators of PRICE and the Pakistan Institute of Living and Learning.

Competing Interest: The authors have declared that no competing interests exist.

Funding: PRICE, a founding member of CRIT Care Asia is funded by Wellcome Innovations grant awarded to Oxford University (award code) 215522 and by ISARIC grant (222048/Z/20/Z)

\section{References:}

1. Fauci AS, Lane HC, Redfield RR. Covid-19—navigating the uncharted. Mass Medical Soc; 2020. 
2. Guan W-j, Ni Z-y, Hu Y, Liang W-h, Ou C-q, He J-x, et al. Clinical characteristics of coronavirus disease 2019 in China. New England journal of medicine. 2020;382(18):1708-20.

3. https://covid.gov.pk/stats/pakistan . accessed $7^{\text {th }}$ December 2021.

4. Tahir S, Tahir SA, Arif TB, Majid B, Majid Z, Malik F, et al. Epidemiological and clinical features of SARS-CoV-2: a retrospective study from East Karachi, Pakistan. Cureus. 2020;12(6).

5. Ahmad M, Beg BM, Majeed A, Areej S, Riffat S, Rasheed MA, et al. Epidemiological and clinical characteristics of COVID-19: a retrospective multi-center study in Pakistan. Frontiers in Public Health. 2021;9:342.

6. Asghar MS, Kazmi SJH, Khan NA, Akram M, Khan SA, Rasheed U, et al. Clinical profiles, characteristics, and outcomes of the first 100 admitted COVID-19 patients in Pakistan: a single-center retrospective study in a tertiary care hospital of Karachi. Cureus. 2020;12(6).

7. Nasir N, Habib K, Khanum I, Khan N, Muhammad ZA, Mahmood SF. Clinical characteristics and outcomes of COVID-19: Experience at a major tertiary care center in Pakistan. The Journal of Infection in Developing Countries. 2021;15(04):480-9.

8. Hashmi, M., Beane, A., Taqi, et. al. Pakistan Registry of Intensive CarE (PRICE): Expanding a lower middle-income, clinician-designed critical care registry in South Asia. Journal of the Intensive Care Society 2018 0(0) 1-6

9. CRIT Care Asia1,2*; Madiha Hashmi3*, MD ; Abi Beane1*, MSc, PhD ; Srinivas Murthy4, MD, MHSc ; Arjen M Dondorp1, MD, PhD ; Rashan Haniffa5, MD, DPhil . Leveraging a Cloud-Based Critical Care Registry for COVID-19 Pandemic Surveillance and Research in Lowand Middle-Income Countries. JMIR Public Health Surveill 2020;6(4):e21939

10. Elkin PL, Brown SH, Husser CS, Bauer BA, Wahner-Roedler D, Rosenbloom ST, et al. Evaluation of the content coverage of SNOMED CT: ability of SNOMED clinical terms to represent clinical problem lists. Mayo Clin Proc 2006 Jun;81(6):741-748. [CrossRef] [Medline]

11.Collaboration for Research, Implementation and Training in Critical Care - Asia Investigators, Pisani L, Rashan T et al. Performance evaluation of a multinational data platform for critical care in Asia [version 1; peer review: 1 approved]. Wellcome Open Res 2021, 6:251 (https://doi.org/10.12688/wellcomeopenres.17122.1) 